DOI: $10.14451 / 2.144 .21$

\title{
СОВРЕМЕННОЕ РАЗВИТИЕ НОТАРИАТА КАК ДЕЙСТВЕННОГО ИНСТИТУТА ПРЕВЕНТИВНОГО ПРАВОСУДИЯ
}

\author{
(c) 2020 Скачкова Ольга Сергеевна \\ доцент кафедры гражданского и арбитражного процесса \\ Самарский государственный экономический университет, Россия, Самара \\ E-mail:yarmoluik@mail.ru
}

(c) 2020 Чугурова Татьяна Викторовна

кандидат юридических наук, доцент кафедры гражданского и арбитражного процесса

Самарский государственный экономический университет, Россия, Самара

E-mail: ChugurovaTV@yandex.ru

(C) 2020 Шевченко Юлия Вадимовна

магистрант факультета магистратуры

Самарский государственный экономический университет, Россия, Самара

E-mail: yarmoluik@mail.ru

В настоящей статье рассматривается процесс развития института нотариата как превентивного правосудия. За последние несколько лет, реформирование нотариальной деятельности дало возможность возложить на институт нотариата функции, не только по оказанию квалифицированной юридической помощи, но и по предупреждению и разрешению конфликтных ситуаций в досудебном порядке, что в свою очередь сказалось и на процессе повышения эффективности правосудия.

Ключевые слова: нотариат, судебная система, правосудие, превентивное правосудие, бесспорные требования, исполнительная надпись, приказное производство, медиация

А.Л.Миронов в своей работе приводил цитату известного ученого Жобера, который еще в начале 1897 г. отметил, что «нотариусы сопровождают человека в мир права» [14; с.141]. Исторически так сложилось, что возникновение нотариата было связано с необходимостью оказания содействия участникам гражданского оборота в совершении сделок, юридической охране их прав и фиксации совершаемых ими действий.

K сожалению, почему то так сложилось, что функция оказания квалифицированной правовой помощи целиком и полностью переносилась на институты адвокатуры, без упоминания того, что в данном процессе достаточно важную роль выполняют и органы нотариата [14; с.141]. Однако за последние несколько лет, в связи с повышением внимания к проблемам защиты прав и свобод граждан и юридических лиц, закрепленное в статье 48 Конституции РФ право на получение качественной правовой помощи стало толковаться более расширительно и наряду с адвокатами, была признана одной из важнейших, и правозащитная деятельность нотариата [1].

Как отмечает П.А. Кучеренко, нотариус занимает особое место в российском праве, находясь на стыке между частным и публичным правом он с одной стороны, выступает как представитель государства (при этом, не относясь ни к одной из существующих ветвей власти) а с другой, как независимый помощник, призванный решать возникающие юридические вопросы у субъектов правоотношений [13; с.217].

Нотариальная деятельность по своему характеру носит некоммерческий характер и не может быть направлена на извлечение прибыли, что вполне справедливо, учитывая ее полномочия и особый государственно-публичный статус.

Обращая внимание на функции, которые свойственны рассматриваемому правовому институту, нужно отметить, что поэтому поводу существует много мнений и проведено немало научных исследований. Нам наиболее близка классификация, предложенная Г.Г. Черемных и И.Г.Черемных, которые выделяли следующие функциональные группы [17; с.32]:

1. публично-правовые;

2. частно-правовые.

Данное деление как раз наиболее полно подчеркивает дуалистическую природу нотариата, вызванную необходимостью выступая одновре- 
менно и представителем государства, оказывать максимально полное содействие в защите индивидуальных интересов клиентов.

Первая группа функций внутри себя имеет деление на подгруппы: - правоохранительную;-правоприменительную;-предупредительнопрофилактическую (сюда входит обеспечение доказательств и разрешение гражданских дел бесспорного характера). Последнюю подфункцию исследователи нередко называют «предупредительным правосудием».

Надо отметить, что в связи проведением административной и судебной реформы, направленной на повышение качества оказания юридической помощи гражданам и организациям, улучшения правосудия и снижения нагрузки на судебные органы, было пересмотрено сложившееся отношение к нотариату и сделан упор на развитие его возможностей в разрешении конфликтных ситуации, в связи с чем, представителей данной профессии наделяют особыми функциональными полномочиями в данной сфере [13; с.217].

Так сложилось, и по большому счету, нет смыла опровергать положение о том, что отечественный нотариат призван содействовать только закреплению и формированию взаимных прав у сторон правоотношений, путем удостоверения договоров, выдаче доверенностей и совершению иных действий. Однако в последнее время, все чаще отмечается, что все эти действия можно рассмотреть с несколько иной точки зрения-профилактической - так нотариус, участвуя в процессе согласования условий гражданско-правового договора или брачного контракта, предупреждает возможные споры между его субъектами, тем самым снижая количество судебных дел. В связи с этим открывается новый взгляд на его значение - правовой миротворец или орган предупредительного (превентивного) правосудия.

Превентивное правосудие - это концепция в соответствии с которой специально уполномоченным лицом осуществляется деятельность по предотвращению совершения противоправных действий субъектами правоотношений, разрешению возникающих конфликтов в досудебном порядке.

Ю.Н. Молдованова отмечает, что в отечественной юридической науке возможность применения вышеуказанной дефиниции к нотариату является достаточно спорной [15; с.101]. Сама по себе, предупредительная природа нотариальных действий сомнений не вызывает, но вот применение в сочетаний с ней термина «правосудие» кажется не совсем верным, поскольку согласно Конституции РФ единственным органом, уполномоченным на осуществление данной деятельности, является суд. Но такой подход не представляется в полной мере оправданным, поскольку применительно к нотариусу и его роли в предупреждении и разрешении конфликтов бесспорного характера, упор нужно делать на профилактику, и предотвращение желания у сторон продолжать развивать свой спор в дальнейшем и искать его разрешения в других уполномоченных инстанциях.

Идея обозначения нотариальной деятельности как превентивного правосудия пришла в доктрину российского права из-за границы, из стран где функционирует нотариат латинского типа. Так в Японии, нотариус рассматривается исключительно как инструмент предупреждения гражданско-правовых конфликтов и занимает промежуточное положение между государственными служащими [17; с.35].

Для нашего общества такое отношение к нотариату не свойственно, может потому что в России нотариус все-таки выступает в качестве частного лица, не находящегося на государственной службе (за исключением государственных нотариусов), и следовательно возникает меньше доверия к его способностям по урегулированию спорных ситуаций.

Тем не менее, возможность реализации с помощью нотариальных действий, превентивных функций действующим законодательством предусмотрена путем закрепления права осуществления следующих действий: совершения исполнительных надписей (ст.90 «Основ законодательства Российской Федерации о нотариате» (утв. ВС РФ 11.02.1993 № 4462-1) [2], удостоверения соглашений о взыскании алиментов (ст. 100 Семейного кодекса РФ) [3]; обращение взыскания на заложенное имущество на основании нотариального удостоверенного соглашения (глава XVI.1 «Основ законодательства Российской Федерации о нотариате» (утв. ВС РФ 11.02.1993 № 4462-1); заключение медиативного соглашения (ст. 59.1 «Основ законодательства Российской Федерации о нотариате» (утв. ВС РФ 11.02.1993 № 4462-1).

Следует отметить, что современный этап российской судебной реформы, ставит перед со- 
бой задачу снижения уровня нагрузки на судебный аппарат путем расширения возможностей граждан для разрешения, возникающих между ними споров в досудебном порядке. И здесь бесспорно следует согласиться с тем выводом, что нотариат, как никто другой способен помочь в разрешении данной проблемы.

Так, как указывает А.Л. Миронов, исполнительная надпись нотариуса является одним из самых наиболее часто используемых способов принудительного исполнения обязательств и относится к несудебным формам защиты нарушенных интересов сторон [14; с.143].

Однако ряд исследователей полагает, что такое нотариальное действие как совершение исполнительной надписи, прямо противоречит положениям Конституции РФ, в той части, где указано, что лишение гражданина имущества возможно только на основании решения суда. С подобным мнением нельзя согласиться, поскольку оно противоречит выводам Конституционного Суда РФ (далее КС РФ). Так, согласно определению КС РФ от 05.02.1998 г. № 21-О5, взыскание на основании исполнительной надписи нотариуса не противоречит действующему законодательству и не нарушает права и законные интересы лиц, поскольку при совершении данного действия должник не лишается права на защиту, в том числе и посредством обращения в суд [6]. Также следует учитывать, что критерием правомерного совершения исполнительной надписи выступает бесспорность задолженности и ее призвание должником, отсутствие противоречий между сторонами о сроках и размерах требования.

Если обращаться к судебному способу разрешения спора, то там тоже предусматривается возможность разрешать бесспорные требования сторон в упрощенном порядке. Речь идет о приказном производстве, которое в принципе позволяет оперативно разрешать заявленные требования. Надо отметить, что у данного института имеется немало недостатков связанных со сроками рассмотрения, низким уровнем гарантий защиты процессуальных прав сторон участвующих в деле: несоблюдение принципов диспозитивности, гласности, устности, отсутствие у должника возможности предъявлять возражения во время рассмотрения дела в суде, сокращенные сроки обжалования вынесенного судебного акта [10; с.314].

Указывая на имеющиеся недостатки в при- казном производстве, целый ряд авторов, включая Н. А. Громошину [11; с.327], Н. А. Рассахатскую [17; с.106], считали необходимым закрепить данный институт в качестве альтернативного способа разрешения спора, который передается на рассмотрения в соответствующий административный орган. Связано это с тем, что приказное производство, ввиду его упрощенного характера, значительно снижет качество правосудия и ограничивает возможности одной из сторон по обжалованию правоприменительного акта. И здесь как раз можно сказать, что нотариат способен принять на свою компетенцию дела приказного характера, и в какой - то степени это даже позволит поднять эффективность их разрешения.

Отдельное внимание в рамках рассматриваемой темы следует уделить изучению процедуры совершения исполнительной надписи, чтобы увидеть все ее достоинства, позволяющие считать это действие достойной альтернативой приказному производству. Первое на что нужно обратить внимание, это зафиксированный список документов, на основании которых может быть произведено взыскание задолженности на основании исполнительной надписи [2]:

- сделки, получившие нотариальное удостоверение;

- кредитные договоры (кроме договоров с микрофинансовыми организациями), договоры поручительства, договоры оказания услуг связи (в случае неисполнения обязательств по оплате оказанных услуг), в случае если в них предусмотрен такой способ взыскания задолженности;

- иные документы в соответствии с Постановлением Правительства РФ от 01.06.2012 г. № 543 «Об утверждении перечня документов, по которым взыскание задолженности производится в бесспорном порядке на основании исполнительной надписи» [5]. Среди них можно выделить залоговый билет, договор проката, хранения и др. Данный перечень является закрытым.

Законом также устанавливаются требования, при соблюдении которых возможно совершение исполнительной надписи на документе:

1. бесспорность требования взыскателя к должнику. Это означает, что документы, на которых основывается заявитель при обращении за совершением нотариального действия, не должны вызывать сомнений в наличие у обратившегося лица права требовать принудитель- 
ного исполнения обязательства в досудебном порядке, должен четко просматриваться размер задолженности, порядок ее исчисления, момент, когда должник считается просрочившим. Такое требование, как взыскание неустойки, штрафов и пеней не может быть удовлетворено за счет совершения исполнительной надписи - другая сторона имеет право опротестовать ее размер, требовать уменьшения и вообще оспаривать законность ее начисления. И в большинстве случаев, как взыскатели, так и сами нотариусы стараются учитывать это на практике.

Так, решением по делу № 2-1097/2019 Центрального районного суда г. Новосибирска, было отказано в удовлетворении иска гражданки А. к. ПАО «Банк ВТБ» и нотариусу Ваиной Л. С. о признании исполнительной надписи нотариуса не подлежащей исполнению [7]. В своем заявлении истица указывала, что между ней и Банком был заключен кредитный договор, в дальнейшем несмотря на то что, она исправно вносила плату за пользование кредитными средствами, с нее была взыскана задолженность по договору на основании исполнительной надписи нотариуса. Считает, что ответчиками был нарушен не только порядок совершения данного нотариального действия, но и сам размер списанной задолженности не правомерен- помимо основной суммы долга и процентов, была взыскана еще и неустойка, порядок и правомерность начисления которой не является бесспорным.

Отказывая в удовлетворении исковых требований, суд исходил из того, что заявление истца об отсутствии бесспорности требований не нашли своего отражения в материалах дела - так, должник получив требование о погашении задолженности мог обратиться в банк и заявить о своем несогласии с ее размером, порядком взыскания, также не был представлен контррасчет, который был подтверждал иную сумму долга по кредитному договору. Доводы о включении в размер задолженности штрафов и пеней не обоснован заявителем, поскольку банком был представлен расчет взысканной суммы, из которого было видно, что ничего иного кроме основного долга и процентов должнику начислено, а в последующем взыскано не было.

2. соблюдение срока обращения к взысканию - со дня, когда обязательство должно быть исполнено, прошло не более чем два года. Данный срок является пресекательным и по его истечению обращение взыскание на основании исполнительной надписи нотариуса не может быть совершено.

Обращаясь к сравнительному анализу института приказного производства и исполнительной надписи, хочется отметить в качестве положительной черты досудебного способа взыскания задолженности, контроль за уведомлением должника. Т.е. нотариус должен уведомить должника о том, что исполнительная надпись совершена, о том, что она будет совершена, а также о том, что будет осуществлено взыскание на заложенное имущество. И в случае несоблюдения этих условий, исполнительная надпись будет являться незаконной и не подлежащей исполнению.

Так, Ухтинский городской суд Республики Коми признал действия нотариуса Б. и отменил его исполнительную надпись, исходя из того, что ответчиком был нарушен порядок совершения нотариального действия, в частности не было соблюдено требование об уведомлении должника о возможности добровольного исполнения обеспеченного залогом обязательства [8].

В приказном производстве таких строгих процессуальных требований не предусмотрено - должник не извещается о начале приказного производства, у него сокращенный срок на обжалование судебного приказа, а также факт его не получения не всегда признается судом как основание для его отмены.

Исходя из этого, можно сделать вывод о том, что институт исполнительной надписи нотариуса имеет достаточно много преимуществ, которые позволяют говорить о том, что он выступает более законным и обоснованным средством для разрешения дел, в которых отсутствует спор о праве. Безусловно, имеются недостатки технического и правового характера: труднодоступное расположение нотариальных контор, не ограниченность право взыскателя на обращение за совершением нотариального действия к любому нотариусу вне зависимости от места жительства должника или заявителя, одновременно с процессом взыскания может идти и еще судебное разбирательство в рамках тех же требований [10; с.315].

В связи с этим, возможно, следует пересмотреть главы Основа законодательства о нотариате посвященные регулированию института исполнительной надписи нотариуса и скорректировать их в целях предотвращения возможности злоупотребления взыскателями своими 
правами. Однако, несмотря на имеющееся несовершенство правовых норм, следует отметить, что в общей статистике судебных исков, связанных с обжалованием совершенных нотариальных действий, оспаривание взыскания совершенного на основании исполнительной надписи является далеко не распространенным исковым требованием, что свидетельствует о том, что в целом данный институт функционирует достаточно неплохо и требования законодательства о нотариате не нарушаются.

Как отмечает Т.Е. Алешина, современный период реформирования отечественной судебной системы, характеризуется активным поиском эффективных механизмов правового урегулирования конфликтных ситуаций без обращения в судебные органы [9; с.143]. Как мы, уже смогли убедиться институт нотариата наделен действенными средствами, которые позволяют ему участвовать в разрешении дел, в которых отсутствует спор о праве, что является достаточно логичным, поскольку нотариус не является органом осуществляющим правосудие и не обладает в полной мере той компетенцией, которая позволяет разрешать подобные ситуации. Однако стоит обратить внимание на возможность участия нотариуса в альтернативных способах урегулирования споров с участием посредника.

Федеральный закон от 08.2010193-Ф3 «Об альтернативной процедуре урегулирования споров с участием посредника (процедуре медиации)» [4] (далее ФЗ № 193) вводит понятие медиации под которой следует понимать - способ разрешения конфликтных ситуаций при содействии независимого лица на основе добровольного согласия сторон с целью достижения ими компромисса в рамках рассматриваемого дела.

Ни один нормативно-правовой на сегодняшний день не определяет перечень лиц, которые могут выступать в качестве медиаторов. Главное, чтобы они соответствовали требованиям, указанным в ст. 15 и 16 ФЗ № 193. Статья 15 предусматривает условия к лица, осуществляющим медиаторскую деятельность на непрофессиональной основе: достижение возраста 18 лет; обладании полной дееспособностью; отсутствие судимости.

Осуществлять деятельность медиатора на профессиональной основе могут лица, достигшие возраста 25 лет, имеющие высшее образование и получившие дополнительное образование в сфере применения медиации. Из этого можно сделать вывод, что в действующей редакции ст. 16 Закона о медиации, нотариус не указывается в качестве субъекта способного проводить медиативные процедуры [4].

До 2019 г. одной из проблем медиативного соглашения было невозможность обеспечить его принудительное исполнение, минуя стадию обращения в суд за выдачей исполнительного листа. Теперь, начиная с октября 2019 г. вступили в законную силу изменения Основ законодательства о нотариате - появилась ст.59.1, наделяющая нотариуса правом удостоверять медиативные соглашения, при обязательном участии медиатора [2]. Т.е, если удостоверенный нотариусом документ, не исполняется одной из сторон, то его можно сразу же передать в банк или судебным приставам-исполнителям в качестве основания для возбуждения исполнительного производства. И указанные органы, и их должностные лица обязаны начать исполнение по поступившему соглашению, как по обычному исполнительному документу.

Для того, чтобы удостоверить медиативное соглашение в нотариальном порядке необходимо личное присутствие сторон и медиатора, а также наличие подлинников всех необходимых документов: договоров (контрактов, а также спецификаций, заявок, дополнительных соглашений, информационных писем, и др.); документы, подтверждающие полномочия представителей, медиатора; справки, выписки с расчетных счетов, акты сверок взаимных расчетов и т.д.

По мнению практикующего медиатора Алексея Кравцова, нотариальное оформление медиативного соглашения дает огромный толчок для развития не только института медиации, но и самого нотариата и судебной системы [12]. В-первую очередь, это конечно же, сокращение процессуального времени которое необходимо затратить для получения исполнительного листа и начать процедуру принудительного взыскания - так при обращении в суд данный процесс занимает 15 месяцев, в третейском суде1,5 месяца. Также если раньше низкая популярность медиации объяснялась добровольностью исполнения достигнутого соглашения, то теперь стороны получает возможность полностью контролировать процесс взыскания дебиторской задолженности, экономя собственное время и денежные средства - не придется оплачивать государственную пошлину за обращение в суд, 
участвовать в длительных судебных процессах. Да и суд получает прекрасную возможность «разгрузить свою работу» по рассмотрению части хозяйственных и экономических споров.

Надо сказать, что в целом юридическое сообщество отнеслось достаточно положительно к данному нововведению, а президент Федеральной нотариальной палаты Константин Корсик отметил, что «придание медиативному соглашению исполнительной силы с помощью нотариального акта подтверждает необходимость расширения сферы компетенции нотариуса для стабилизации гражданского оборота в целом, а также значимости такой функции нотариальной деятельности как превентивного правосудия» [12].

Также в качестве будущего развития не только медиации, но и нотариата, можно вполне предположить что именно на данный институт будет возложена обязанность не только по удостоверению, но и по заключению медиативного соглашения, т.е. нотариус сможет выступать медиатором. И надо сказать, что для этого имеются все объективные предпосылки.

Так, нотариус не является и не может являться заинтересованной стороной в совершении тех или иных правовых действий, а ограничения в виде запрета на осуществление предпринимательской или иной деятельностью приносящей доход, позволяют сделать вывод о том, что все нотариальная действия будут совершаться исходя из требований закона, а не корысти, и исключается возможность подкупа должностного лица [9; с.147].

Нотариус, как лицо, обладающее высшим юридическим образованием сможет квалифицированно объяснить сторонам все правовые последствия заключения медиативного соглашения, какие могут быть иные выходы из сложившейся ситуации. Напомним, что действующие на настоящий момент требования к медиаторам не «настаивают» на наличии у них высшего юридического образования, поэтому возможно, что их варианты решения конфликта не всегда продиктованы и основаны на правовых предписаниях.

Также следует не забывать и об обязанности нотариуса соблюдать профессиональную тайну, и получается что, по сути, конфиденциальность медиации уже заложена в саму суть профессии и является одной из важнейших юридических обязанностей [9; с.147]. За нарушение нотариаль- ной тайны, лицо будет нести ответственность, регламентированную нормами законодательства о нотариате, которая гораздо серьезнее, чем медиативная.

Как следует из вышеизложенного, нотариус вполне может претендовать на возможность осуществлять медиаторскую деятельность, поскольку заложенные в его профессии принципы и обязанности, наиболее эффективно позволят повысить уровень доверия к процедуре медиации и правовой обоснованности, заключаемых в ходе нее соглашений.

Разумеется, для того, чтобы нотариус смог выступать в качестве медиатора, должны быть внесены соответствующие поправки в нормы законодательства о нотариате. Так, должно быть закреплено, что нотариус не является и не должен являться причиной возникновения разногласий между сторонами; нотариус не может придерживаться какой-либо позиции в споре, он должен сохранять нейтральность и действовать в рамках закона; прежде принимать какое-либо решение относительно способа урегулирования конфликта, нотариус обязан изучить все обстоятельства дела, включая мнения сторон; все совершаемые нотариусом действия должны способствовать реальному исполнению достигнутого соглашения [9; с.148].

Первое медиативное соглашение, удостоверенное нотариусом, было заключено в ноябре 2019 г. [12]. И хочется, надеется, что в будущем, мы сможем увидеть увеличение случаев разрешения споров с помощью процедуры медиации, потому что данный инструмент безусловно имеет немало преимуществ, просто нужно суметь ими воспользоваться и применить в надлежащем виде.

Подводя итог настоящему исследованию, следует отметить, что за последние несколько лет, понимание такой функции нотариата как «превентивное правосудие» значительно изменилось - теперь нотариусу предоставляется гораздо больше возможности по урегулированию целого ряда вопросов связанных с исполнительным производством, медиацией. Данные меры осуществляются не только в рамках реформы нотариальной деятельности, но и судебной, поскольку они направлены на снижение нагрузки на суды, и стимулированию сторон к решению возникающих у них вопросов в досудебном порядке. И расширение сферы нотариальных полномочий является достаточно оправданным 
шагом, поскольку именно данный институт, благодаря своим принципам и историческим основам, способен оказать содействие в мироном разрешении целого ряда вопросов.

Конечно же, остается надеется на то, что это были далеко не последние законодательные изменения норм о нотариате и в дальнейшем, развитие нотариата как превентивного правосудия только продолжиться. Это в свою очередь позволит не только эффективно обеспечить право граждан и организаций на получение квалифицированной юридической помощи, но и позволит предупреждать многочисленные правовые конфликты, выявлять их и в оперативном режиме разрешать.

\section{Библиографический список}

1. Конституция Российской Федерации (принята на всенародном референдуме 12.12.1993). М.: Эксмо, 2019.

2. Основы законодательства Российской Федерации о нотариате (утв. ВС РФ 11.02.1993 № 4462-1) (с изм. и доп., вступ. в силу с 01.01.2020) [Электронный ресурс] // - Режим доступа: http://www.consultant.ru/ document (обращения: 25.02.2020).

3. Семейный кодекс Российской Федерации от 29.12.1995 № 223-Ф3 (ред. от 06.02.2020) [Электронный ресурс] // - Режим доступа: http://www.consultant.ru/document (обращения: 28.02.2020).

4. Федеральный закон от 27.07.2010 № 193-Ф3 «Об альтернативной процедуре урегулирования споров с участием посредника (процедуре медиации)» (последняя редакция) [Электронный ресурс]// - Режим доступа: http://www.consultant.ru/document (обращения: 28.02.2020).

5. Постановление Правительства Российской Федерации от 01.06 .2012 г. № 543 «Об утверждении перечня документов, по которым взыскание задолженности производится в бесспорном порядке на основании исполнительной надписи» (последняя редакция) [Электронный ресурс]// - Режим доступа: http://www. consultant.ru/document (обращения: 28.02.2020).

6. Определение Конституционного суда Российской Федерации от 05.02.1998 № 21-О5 «По проверке жалобы гражданина Носкова Д.А. на нарушение его конституционных прав п.5 ст. 338 Гражданского процессуального кодекса РСФСР» [Электронный ресурс]// - Режим доступа: http://www.consultant.ru/document (обращения: 28.02.2020).

7. Решение Центрального районного суда г. Новосибирска от 13.02.2019 г. по делу № 2-1097/2019 [Электронный ресурс]// - Режим доступа: http://www.sudact.ru (обращения: 29.02.2020).

8. Решение Ухтинского городского суда Республики Коми от 21.02.2018 по делу № 2-1276/2017.

9. Алешина T.E. Некоторые вопросы медиации в практике российского нотариата как субъекта реализации охранительной функции права// Т.Е.Алешина// Вестник Саратовской государственной юридической академии. 2016. № 2. С. 143-148.

10. Божко А.П., КавкаеваЮ.А., РудневаЮ.В., Фадеев А.В. О некоторых проблемах приказного производства/ А. П. Божко, Ю. А. Кавкаева, Ю. В. Руднева, А. В. Фадеев// Вестник Волжского университета им. В. Н. Татищева. 2019. № 3 (Т.1). С. 312-319.

11. Громошина Н.А. Дифференция и унификация в гражданском судопроизводстве: дисс., д-ра юрид.наук. М., 2010. С. 327-329.

12. Куликов В., Кравцов А. «Россияне начали мириться с помощью нотариусов»// Российская газета. 2020. [Электронный ресурс]// - Режим доступа: http://rg.ru (обращения: 29.02.2020).

13. Кучеренко П.А. Правозащитная функция современного нотариата/ П.А. Кучеренко// Вестник Российского университета дружбы народов. Серия: Юридические науки. 2015. № 1. С. 216-221.

14. Миронов А.Л. Нотариат как институт превентивного, предупредительного правосудия/ А.Л. Миронов// Вестник Московского университета МВД России. 2008. № 2. С.141-149.

15. Молдованова Ю.Н., Тарбагаева Е.Б. «Превентивное правосудие» - лингвстический аспект/ Ю.Н. Молдованова, Е. Б. Тарбагаева// Юрислингвистика. 2016. № 2. С.100-106.

16. Рассахатская Н.А. Некоторые проблемы оптимизации гражданского судопроизводства/ Н.А.Рассахатская// Судебная реформа и проблемы развития гражданского и арбитражного процессуального законодательства. Материалы международной научно-практической конференции. 2012. С.105-111.

17. Черемных Г.Г., Черемных И.Г. Нотариальное прав РФ. Учебник/ Г. Г. Черемных, И. Г. Черемных.-М.: Эксмо, 2011. 312 c. 